\title{
Local microcircuitry of parasubiculum shows distinct and common features of excitatory and inhibitory connectivity
}

\author{
Rosanna P Sammons ${ }^{1 *}$, Alexandra Tzilivaki ${ }^{1,2}$, Dietmar Schmitz ${ }^{1-6^{*} \dagger}$
}

1 Charité-Universitätsmedizin Berlin, corporate member of Freie Universität Berlin, HumboldtUniversität zu Berlin, and Berlin Institute of Health, Neuroscience Research Center, 10117 Berlin, Germany

2 Einstein Center for Neurosciences, 10117 Berlin, Germany

3 Berlin Institute of Health, 10178 Berlin, Germany

4 German Center for Neurodegenerative Diseases (DZNE) Berlin, 10117 Berlin, Germany

5 Cluster of Excellence NeuroCure, 10117 Berlin, Germany

6 Bernstein Center for Computational Neuroscience Berlin, Germany

*Correspondence: Dietmar Schmitz, Email: dietmar.schmitz@charite.de; Rosanna P. Sammons, Email: rosanna.sammons@charite.de

${ }^{\dagger}$ Lead contact

\section{Abstract}

The parasubiculum is located within the parahippocampal region, where it is thought to be involved in the processing of spatial navigational information. It contains a number of functionally specialised neuron types including grid cells, head direction cells and border cells, and provides input into layer 2 of the medial entorhinal cortex where grid cells are abundantly located. The local circuitry within the parasubiculum remains so far undefined but may provide clues as to the emergence of spatially tuned firing properties of neurons in this region. We used simultaneous patch-clamp recordings to determine the connectivity rates between the three major groups of neurons found in the parasubiculum. We find high rates of interconnectivity between the pyramidal class and interneurons, as well as features of pyramid to pyramid interactions indicative of a non-random network. The microcircuit that we uncover shares both similarities and divergences to those from other parahippocampal regions also involved in spatial navigation. 


\section{Introduction}

The parahippocampal region (PHR) is home to several different types of functionally specialised neurons, thought to underpin the creation of an internal map of an animal's external environment, and therefore, enabling successful navigation through this environment and allowing for spatial learning. These specialised neuron types include grid cells, head-direction cells and border cells (Moser et al., 2015). These cell types have been reported in multiple subregions of the PHR including the MEC, where grid cells were first discovered (Hafting et al., 2005), the presubiculum and the parasubiculum (Boccara et al., 2010; Taube, 1995). Until recently much of the focus on navigational circuitry was directed at the hippocampus and the medial entorhinal cortex (MEC). However, the PaS has attracted increasing attention thanks not only to the discovery of spatially tuned neurons present in this region, but also due to its location within the parahippocampal circuitry. The PaS receives inputs from the medial septum (Unal et al., 2015), a key pacemaker for theta oscillations, and sends outputs to layer 2 of the MEC (Caballero-Bleda and Witter, 1993; van Groen and Wyss, 1990; Köhler, 1986), where the majority of grid cells are located. Based on this, it is a prime candidate to influence the spatially tuned cells of the MEC, as well as exhibiting its own spatial signals. Thus far, numerous models have been proposed for the generation of grid cell firing patterns (Burak and Fiete, 2009; Burgess et al., 2007; Hasselmo et al., 2007; McNaughton et al., 2006). Despite these models, the exact mechanisms underlying spatially tuned firing properties are still unresolved. Mapping out the fine details of the microcircuitry in which these cells sit is an essential step to further develop our understanding and determine how grid cell firing emerges, and how this in turn supports memory formation. Recently, the local circuitry of the superficial layers of the MEC and the presubiculum have been mapped out using multiple, simultaneous patchclamp recordings (Fuchs et al., 2016; Peng et al., 2017; Winterer et al., 2017). In comparison, little is known about the connectivity within the parasubiculum, with only indirect, anatomical evidence of projections (Burgalossi et al., 2011; Funahashi and Stewart, 1997). Here, we use simultaneous patchclamp recordings to resolve the local microcircuitry of the three major cell classes found in the parasubiculum. Our findings draw parallels to work from the presubiculum and MEC, as well as showing distinct topological differences, suggesting that while models for grid cell generation may be shared across brain regions, wiring is tailored to each region for their specific roles in the wider circuitry.

\section{Results}


bioRxiv preprint doi: https://doi.org/10.1101/2020.12 18.423400; this version posted December 19, 2020. The copyright holder for this preprint (which was not certified by peer review) is the author/funder, who has granted bioRxiv a license to display the preprint in perpetuity. It is made available under aCC-BY-NC-ND 4.0 International license.

We recorded simultaneously from up to 7 neurons in a whole-cell patch-clamp configuration in the parasubiculum, to elucidate the microcircuitry within this region (Fig 1A). Previously, we have shown that neurons in the parasubiculum can be broadly classified into three groups: fast-spiking putatively PV-expressing interneurons, a broad class of non-fast-spiking interneurons often superficially located and reelin-expressing, and a large class of pyramidal neurons typically expressing WFS1 (Sammons et al., 2019). We used these groups to classify our recorded neurons, using a combination of immunolabelling and electrophysiological properties (see methods, Table S1; for electrophysiological properties of the three cell classes see Table S2). Thus, we were able to establish a connectivity scheme between these main subgroups of neurons in the parasubiculum (Fig 1B-C). For all connections where the presynaptic cell was classified in one of the two interneuron classes IPSPs were seen in the postsynaptic cell, leading us to believe that our classification could robustly separate excitatory and inhibitory neurons. Pyramidal neurons form the biggest cell class in the parasubiculum. We observed a connectivity rate of $4 \%$ between cells of this class ( 25 / 622 tested connections; Fig 1B). Reciprocal connections were observed between three separate pairs of pyramidal neurons ( 3 / 311 pairs tested, $0.96 \%$ ). This observed frequency is higher than expected based on a $4 \%$ connectivity rate (expected likelihood of reciprocal connectivity: $4 \% \times 4 \%=0.16 \%, p=0.014$, binomial test), suggesting a nonrandom organisation of connectivity between pyramidal neurons in the parasubiculum.

We found connections between both classes of inhibitory neurons and the pyramidal class of cells. Specifically, non-fast-spiking interneurons connected onto pyramidal cells at a rate of $13 \%$ ( 5 / 38 tested connections), while fast-spiking neurons showed a $44 \%$ connectivity rate onto pyramidal cells (17 / 39 tested connections). In the opposite direction, pyramid neurons contacted non-fast-spiking neurons at a relatively low rate $(2.6 \%, 1 / 38$ test connections, unidirectional), but contacted fast-spiking neurons at a rate of $23 \%$ (9 / 39 tested connections). Between pyramidal and fast-spiking neurons 5 reciprocally connected pairs were found (5 / 39 pairs, $12.8 \%$ ). Given the individual connectivity rates between these two cell classes the number of reciprocal pairs found was not different from expected (expected likelihood of reciprocal connectivity: $44 \% \times 23 \%=10.1 \%, p=0.591$, binomial test).

\section{Pyramid to pyramid connections in the parasubiculum}

The pyramidal class of neurons consisted of WFS1-positive immunolabelled neurons, as well as nonlabelled neurons with comparable electrophysiological profiles (Fig 2A1). Connections between this 
bioRxiv preprint doi: https://doi.org/10.1101/2020.12 18.423400; this version posted December 19, 2020. The copyright holder for this preprint (which was not certified by peer review) is the author/funder, who has granted bioRxiv a license to display the preprint in perpetuity. It is made available under aCC-BY-NC-ND 4.0 International license.

class of neurons produced EPSPs in the postsynaptic cell (Fig 2A2) confirming the excitatory nature of WFS1 neurons. The amplitude of these connections followed a log-normal distribution, with many small EPSPs and a small number of large EPSPs (median EPSP amplitude $0.43 \mathrm{mV}$ [0.17 - 0.89 IQR]; Fig 2B). EPSPs between pyramidal neurons had a median latency of $1.55 \mathrm{~ms}$ [1.2 - $2.65 \mathrm{IQR}]$, mean halfwidth of $15.4 \pm 8.6 \mathrm{~ms}$ and a mean risetime of $2.1 \pm 1.0 \mathrm{~ms}$ (Fig $2 \mathrm{C}-\mathrm{E}$ ). In contrast to other brain regions, we did not find bidirectional connections to be stronger than unidirectional connections in the parasubiculum (Table S3) (Cossell et al., 2015; Peng et al., 2017; Song et al., 2005). However, bidirectional connections did have significantly smaller halfwidths and risetimes than unidirectional connections (Table S3). We next aimed to determine if there was any spatial influence of connectivity by looking at the intersomatic distance between recording pairs (Fig 2F). The median intersomatic distance between recorded pyramidal cell pairs was $87 \mu \mathrm{m}$ [66 - 112 IQR]. The connectivity rate did not significantly differ across the range of intersomatic distances tested. Another spatial aspect that could influence connectivity is laminar organisation. The laminar structure of the parasubiculum in rodents is ambiguous, however (Mulders et al., 1997; Tang et al., 2016). Thus, we used a minimal distance to pia measure to examine connectivity along the superficial-to-deep axis. For each pair of recorded neurons, the minimum distance to pia measure of the postsynaptic cell was subtracted from that of the presynaptic cell, such that connections projecting from a deep to a more superficial cell would have a positive projection distance and connections from a superficial to a deeper cell would have a negative projection distance. Connectivity occurred in both directions and was not significantly more likely to occur in one direction more than the other (Fig 2G).

\section{Inhibition onto pyramidal neurons in the parasubiculum}

Inhibitory connections were observed from both non-fast-spiking and fast-spiking interneurons onto pyramidal neurons in the parasubiculum (Fig 3A-B). The amplitudes of IPSPs from non-fast-spiking neurons and fast-spiking neurons were not significantly different from one another (Fig 3C; median IPSP non-fast-spiking to pyramid: $-0.29 \mathrm{mV}[-0.38--0.21]$, median IPSP fast-spiking to pyramid: $-0.32 \mathrm{mV}$ [$0.71--0.23$ ]; $p=0.265$, Mann-Whitney $U$ ). In contrast, the latency of IPSPs from fast-spiking neurons was significantly shorter than IPSPs from non-fast-spiking neurons onto pyramidal-like neurons (Fig 3D; median IPSP latency: non-fast-spiking to pyramid $0.85 \mathrm{~ms}$ [0.85 - 1.3], fast-spiking to pyramid $0.75 \mathrm{~ms}$ [0.6 - 0.8]; $p=0.011$, Mann-Whitney U). The risetime of IPSPs from fast-spiking neurons was also significantly shorter than IPSPs from non-fast-spiking neurons (Fig 3E; median IPSP risetime: non-fast- 
spiking to pyramids $8.4 \mathrm{~ms}$ [5.7 -9.2$]$, fast-spiking to pyramids $1.8 \mathrm{~ms}[1.3-2.5]$; $p=0.009$, MannWhitney U). The halfwidths of IPSPs from the two classes of interneurons onto pyramidal-like neurons did significantly differ (Fig 3F; mean IPSP halfwidth: non-fast-spiking to pyramids $32.4 \pm 16.9 \mathrm{~ms}$, fastspiking to pyramids $21.2 \pm 13.8 \mathrm{~ms} ; \mathrm{p}=0.146$, Student's t-test). No significant differences were seen between uni- and bidirectional connections from fast-spiking interneurons onto pyramids (Table S3). Connectivity rates did not significantly differ across the tested intersomatic distance range for either class of interneuron onto pyramidal cell (Fig 2G-H). Furthermore, we found no directional influence on connectivity rates from either interneuron class onto pyramidal neurons (Fig 2I).

\section{Pyramid to interneuron connections}

We observed only a single connection between pyramidal cells and non-fast-spiking interneurons. In contrast, pyramids frequently contacted fast-spiking interneurons. Similar to pyramid-pyramid connections the amplitudes of pyramid to fast-spiking connections also followed a log-normal distribution (Fig 4A). The median latency of EPSPs was $0.8 \mathrm{~ms}$ [0.8 - 1.2 IQR] (Fig 4B) and median risetime was $1.0 \mathrm{~ms}[0.6-1.2 \mathrm{IQR}]$ (Fig 4C). Mean halfwidth was $7.0 \pm 5.0 \mathrm{~ms}$ (Fig 4D). No differences were observed between uni- and birdirectional connections (Table S3). Furthermore, we found no evidence that intersomatic distance influenced connectivity rate (Fig 4E).

\section{Discussion}

Defining the sub-compartmental microcircuitry of the parahippocampal region is essential to our understanding of information flow through this circuit, as well as establishing how the spatially tuned functional properties of many of the neurons in this region emerge. Here, we describe the local connectivity between the three major cell classes, pyramidal neurons, non-fast-spiking interneurons and fast-spiking interneurons, in the parasubiculum. We find certain aspects of the parasubicular connectivity scheme resemble those from other neighbouring parahipppocampal regions, as well as exhibiting general cortical principles.

The excitatory cells of the parasubiculum form one large class of neurons, and while subtle subclasses may exist the vast majority express the transmembrane protein, WFS1 (Sammons et al., 2019). This homogeneity contrasts with the neighbouring MEC where principal cells can be separated into reelinexpressing stellate and WFS1-expressing pyramidal neurons, with a cell-type specific connectivity 
bioRxiv preprint doi: https://doi.org/10.1101/2020.1218.423400; this version posted December $19,2020$. The copyright holder for this preprint (which was not certified by peer review) is the author/funder, who has granted bioRxiv a license to display the preprint in perpetuity. It is made available under aCC-BY-NC-ND 4.0 International license.

scheme forming between these two classes (Couey et al., 2013; Fuchs et al., 2016; Winterer et al., 2017). Medial to the parasubiculum however, lies the presubiculum whose excitatory population distinctly lack WFS1 expression (Luuk et al., 2008). Previous studies performed in rats have divided presubicular excitatory neurons into superficial and deep (Funahashi and Stewart, 1997), and shown the excitatory connectivity to be highly segregated between these two regions (Peng et al., 2017). Since the mouse parasubiculum shows no obvious delineation between deep and superficial, we treated our excitatory population as one class. The connectivity rate we observed within this class bears a striking resemblance to that of the deep layer presubiculum, both with a connectivity rate of $\sim 4 \%$ and within this, overrepresented reciprocity rates in a similar range. We also observed a log-normal distribution of synaptic weights amongst excitatory connections, seen previously not only in the presubiculum but also in several other brain regions (Cossell et al., 2015; Lefort et al., 2009; Peng et al., 2017; Song et al., 2005). Thus, the excitatory circuitry in the parasubiculum shares commonalities with the deep layers of the presubiculum, as well as expressing features considered to be common principles of cortical connectivity.

We classified inhibitory neurons into either non-fast-spiking and fast-spiking, using reelin and PV respectively as proxies for these two classes. While these two markers alone do not cover the whole breadth of interneurons present in the parasubiculum, together they form a large fraction of inhibitory neurons in the parasubiculum (Sammons et al., 2019), and are known to be expressed in entirely distinct sub-categories of interneurons derived from different streams of the ganglionic eminence during development (Miyoshi et al., 2010; Rudy et al., 2011). We observed connectivity between pyramidal neurons and both classes of interneurons. The two interneuron classes each demonstrated one of the two classical hallmarks of cortical inhibition, namely feed-forward and feedback inhibition. Between pyramids and non-fast-spiking interneurons we observed a heavily skewed connectivity in favour of inhibition onto the pyramids, suggesting that the main excitatory drive onto the non-fast-spiking interneurons originates from an external source and that these neurons may provide feedforward inhibition. This result deviates from work in the presubiculum, where equal levels of recurrent connectivity exist between these two neuron classes (Peng et al., 2017). Given the differences in molecular and cellular composition across these two brain areas (Ding, 2013; Ishihara and Fukuda, 2016) and the heterogeneity that exists among interneurons, it is feasible that the populations of nonfast-spiking neurons vary between the pre- and parasubiculum. Furthermore, the composition of 
bioRxiv preprint doi: https://doi.org/10.1101/2020.12.18.423400; this version posted December 19, 2020. The copyright holder for this preprint (which was not certified by peer review) is the author/funder, who has granted bioRxiv a license to display the preprint in perpetuity. It is made available under aCC-BY-NC-ND 4.0 International license.

different spatially tuned neurons varies across these two neighbouring regions (Boccara et al., 2010). Variations within the microcircuitry may allow for such diverse functional coding. Moreover, inputs into these two neighbouring regions differ, in particular each receives input from different thalamic nuclei (van Groen and Wyss, 1990). Connectivity between fast-spiking interneurons and pyramids was high in both directions. The rate of connectivity from fast-spiking interneurons onto pyramidal neurons (44 \%) was higher than reported in the presubiculum (10 - $25 \%$; Peng et al., 2017) and falls more in line with levels of connectivity seen in cortical regions, including the MEC (Couey et al., 2013; Yoshimura and Callaway, 2005). Parvalbumin interneurons are known for their precision timing and their ability to regulate oscillatory activity, including theta activity (Amilhon et al., 2015; Stark et al., 2013). Neurons in the parasubiculum have been shown to be strongly theta-modulated (Boccara et al., 2010; Glasgow and Chapman, 2007; Tang et al., 2016). In contrast, the presubiculum shows lower levels of theta modulation (Boccara et al., 2010; Preston-Ferrer et al., 2016; Tukker et al., 2015). Thus, the higher level of inhibition from fast-spiking neurons in the parasubiculum may reflect this difference. Reciprocal connections were detected between fast-spiking interneurons and pyramidal neurons, and although they were not overrepresented as observed in the presubiculum (Peng et al., 2017), the high level of interconnectivity between these two cell classes demonstrates a feedback inhibition loop, providing recurrent connectivity proposed by several attractor network models as a basis for grid and head-direction cell firing patterns (Couey et al., 2013; Simonnet et al., 2017).

Distance-dependent connectivity has been demonstrated in several brain regions including presubiculum (Peng et al., 2017), somatosensory cortex (Perin et al., 2011) and visual cortex (Seeman et al., 2018), with connectivity rates usually dropping off with increased intersomatic distance. However, in our study we saw no evidence of distance-dependant connectivity rates, across all connection types. This lack of distance-dependent connectivity has also been reported in the CA3, suggesting that some brain areas may implement different rules of organisation (Guzman et al., 2016). Similarly, we found no evidence of any laminar organisation to connectivity when we looked at the direction of projections across the superficial to deep axis. Previous anatomical work described a predominantly one-way connectivity from superficial to deep cells (Funahashi and Stewart, 1997), which we did not find in our functional recordings. This discrepancy could arise from a number of factors including species differences and distinct technical approaches. The apparent lack of spatial correlation in parasubicular connectivity indicates that perhaps wiring in this region is organised by some higher-order rules, and 
given the relatively small size of the parasubiculum these may not need to be distance-regulated. In cortical areas, it has been shown that cells are more likely to be connected if they share common input, functional properties or if they stem from the same progenitor cells (Cossell et al., 2015; Hofer et al., 2011; Ko et al., 2011; Yoshimura et al., 2005; Yu et al., 2009). Our use of acute slices precludes us from determining spatial tuning properties of the cells we record. However, advancements in imaging technology have recently resulted in calcium imaging in vivo of spatially tuned cells in the MEC, allowing the first spatial analyses of grid cells (Gu et al., 2018; Heys et al., 2014; Sun et al., 2015). Thus, future studies may apply a similar approach to that taken in cortical areas and determine connectivity in acute slices between neurons previously imaged in vivo where the spatial tuning has been discerned (Ko et al., 2011).

In summary, we find that the microcircuitry of the parasubiculum shares some common features with local circuits in other parahippocampal regions, as well as notable distinctions. Our work complements the growing field of connectomics, and more specifically fills a gap in our current knowledge of the navigational circuitry by elucidating the connectivity scheme within the parasubiculum. Moreover, our work supports the notion that local wiring circuits in the brain follow a number of fundamental principles, while region-specific divergences may allow for function-specific processing.

\section{Acknowledgements}

We would like to thank Susanne Rieckmann and Anke Schönherr for excellent technical assistance. This study was supported by Deutsche Forschungsgemeinschaft (DFG; grant numbers: SFB 958, Exc 257), Bundesministerium für Bildung und Forschung (BMBF; grant numbers: Bernstein Center for Computational Neuroscience Berlin grant 01GQ1001A, Bernstein Focus Learning grant 01GQ0972). R.P.S. collected the data. R.P.S and A.T. analysed the data. R.P.S. and A.T. wrote the paper. All authors edited the paper. D.S. secured the funding. D.S. supervised the work.

\section{EXPERIMENTAL MODEL AND SUBJECT DETAILS}

\section{Animals}

All animal maintenance and experiments were performed in accordance with institutional guidelines, guidelines of the local state government (Berlin state government, T0100/03; O0413/12), and the European Union Council Directive 2010/63/EU. 


\section{Electrophysiology}

\section{Slice preparation}

Slices were prepared from adult (postnatal day 50 and over) C57/BI6n mice of both sexes. A small number of slices were taken from transgenic animals being used for additional projects ( $N=109$ animals, $\mathrm{n}=169$ slices in total, of which $\mathrm{N}=79, \mathrm{n}=127$ were wild-type). Animals were anesthetized under isoflurane and decapitated. Brains were removed and transferred to an ice-cold, sucrose-based dissection artificial cerebrospinal fluid (dACSF) containing, in $\mathrm{mM}: 87 \mathrm{NaCl}, 26 \mathrm{NaHCO}_{3}, 50$ sucrose, 10 glucose, $2.5 \mathrm{KCl}$, $1.25 \mathrm{NaH}_{2} \mathrm{PO}_{4}, 0.5 \mathrm{CaCl}_{2}, 3 \mathrm{MgCl}_{2}$, and saturated with $95 \% \mathrm{O}_{2}$ and $5 \% \mathrm{CO}_{2}$. Horizontal slices, $400 \mu \mathrm{m}$ thick, were cut using a vibrating microtome slicer (VT1200S, Leica Biosystems). Once cut, slices were transferred to an interface chamber, which was continuously perfused with ACSF containing, in mM: $119 \mathrm{NaCl}, 26 \mathrm{NaHCO}_{3}, 10$ glucose, $2.5 \mathrm{KCl}, 1.3 \mathrm{MgCl}_{2}, 1 \mathrm{NaH}_{2} \mathrm{PO}_{4}, 2.5 \mathrm{CaCl}_{2}$, saturated with $95 \% \mathrm{O}_{2}$ and $5 \% \mathrm{CO}_{2}$ and maintained at $32-34{ }^{\circ} \mathrm{C}$. Slices were allowed to recover for at least 1 hour before being transferred to a recording chamber.

\section{Whole-cell recordings}

Recordings were performed in a submerged chamber, kept at $32-34{ }^{\circ} \mathrm{C}$, and perfused with the same ACSF as used for interface storage. Somatic whole-cell recordings were performed using glass pipettes pulled from borosilicate glass capillaries with a tip resistance of $3-6 \mathrm{M} \Omega$. Pipettes were pulled using a horizontal DMZ Universal Puller (Zeiss, Germany) and filled with an internal solution containing, in mM: 120 K-Gluconate, 10 HEPES, 10 KCl, 5 EGTA, 2 MgSO4.7H20, 3 MgATP, 3 NaGTP, 5 Phosphocreatine $\mathrm{Na}$. Internal solution also contained $0.2 \%$ Biocytin, to allow for later recovery and identification of recorded neurons. Cells in the parasubiculum were visually identified using infrared differential interference contrast microscopy through a digital camera (XM10-IR, Olympus). Recordings were performed using Multiclamp 700A/B amplifiers (Molecular Devices). Signals were filtered at $10 \mathrm{kHz}$ and sampled at $20 \mathrm{kHz}$, digitised using Digidata 1550 and recorded in pClamp10 (Molecular Devices, USA). Series resistance was calculated from the current deflection to a $-4 \mathrm{mV}$ injection applied in voltage clamp. Pipette capacitance neutralisation and bridge balance were applied and adjusted as appropriate. Liquid junction potential was not corrected for. Upon obtaining a whole-cell patch, neurons were characterised, in current clamp configuration, by injecting increasing steps of negative and positive current. Current injections were applied for $1 \mathrm{sec}$, in increasing steps of $40 \mathrm{pA}$. The voltage responses 
of neurons to these current injections were used to calculate intrinsic properties and action potential parameters. Connectivity was screened by stimulating each cell in turn to produce four action potentials (APs) (1000-4000 pA for 1-2 ms) at $50 \mathrm{~Hz}$. The connectivity screen was carried out in current clamp with cells at resting membrane potential, and while injecting current to hold cells at $-50 \mathrm{mV}$ to elucidate any inhibitory postsynaptic potentials. Connectivity screens consisted of 30-50 sweeps and an average trace was examined for the presence of postsynaptic potentials (PSPs). All PSP parameters were measured from the average response. Onset latency was defined as the time between presynaptic AP peak and onset of PSP. Risetime (10-90 \%) and halfwidth of PSPs were measured in Stimfit (Guzman et al., 2014). Cells were recorded within $250 \mu \mathrm{m}$ of each other. At the end of recording, an image of the slice and electrode placement was taken through a $4 x$ objective to aid with reidentification of the recorded neurons.

\section{Imaging}

\section{Immunohistochemistry}

Following recording slices were fixed in $4 \%$ PFA overnight. Sections were then washed 3 times (5 mins each) in PBS before being incubated in a blocking solution composed of $5 \%$ normal goat serum (NGS, Biozol), $1 \%$ Triton-X (Sigma) and PBS, for 3 hours at room temperature with gentle agitation. Subsequently slices were incubated with primary antibody for 72 hours at $4{ }^{\circ} \mathrm{C}$. Primary antibodies were diluted in a blocking solution composed of $2.5 \%$ NGS, $1 \%$ Triton-X and PBS. To label the biocytin, a conjugated streptavidin marker was used (conjugated to AF 488 or AF 647). Up to three different primary antibodies were used in addition to the biocytin labelling. Following primary incubation slices were washed three times in PBS (20 mins each) and incubated in secondary antibodies for 3 hours at room temperature. Secondary antibodies used were goat anti-rabbit AF 405, goat anti-rabbit AF 647, goat anti-mouse AF 555 or goat anti-guinea pig AF 555, and goat anti-chicken AF 488 (Life Technologies). Finally, slices were washed 4 times ( 15 mins) before being mounted on glass slides in mounting medium (Mowiol).

\section{Confocal microscopy}

Slices were imaged on a Leica TCS SP5 confocal microscope (Leica Microsystems), using $488 \mathrm{~nm}$ (Argon), $568 \mathrm{~nm}$ (solid state) and $633 \mathrm{~nm}$ (Helium, Neon) laser lines. Images were taken through a 20x immersion (0.7 N.A., Leica, pixel size $0.72 \mu \mathrm{m})$ and a $63 x$ (1.4 N.A., Leica, pixel size $0.23 \mu \mathrm{m}$ ) objective 
bioRxiv preprint doi: https://doi.org/10.1101/2020.12.18.423400; this version posted December 19, 2020. The copyright holder for this preprint (which was not certified by peer review) is the author/funder, who has granted bioRxiv a license to display the preprint in perpetuity. It is made available under aCC-BY-NC-ND 4.0 International license.

to provide an overview image and close up of cell somas respectively. Images were acquired at $1024 \mathrm{x}$ 1024 pixels, with a z-step of $2 \mu \mathrm{m}(20 \mathrm{x})$ or $0.5 \mu \mathrm{m}(63 \mathrm{x})$. Images were analysed in Fiji (NIH). Close up images of cell somata were used to determine any post-hoc immunolabelling and overview images were used measure the distance from cell soma to the pia, as well as for matching up cells with their respective recording headstages.

\section{QUANTIFICATION AND STATISTICAL ANALYSIS}

\section{Analysis of Electrophysiological Properties}

Electrophysiological properties were extracted using custom-written python scripts. The following properties were used as input parameters for classification: resting membrane potential $(\mathrm{Vm})$, input resistance, AP threshold, AP height, AHP, mAHP, AP1-AP2 interval, AP9-AP10 interval, adaptation, latency, maximum and minimum $\mathrm{dV} / \mathrm{dt}$, dV/dt ratio, rheobase, sag ratio minimum inter-spike interval, membrane capacitance and membrane time constant. $\mathrm{Vm}$ was taken as the mean across all sweeps of the baseline before current injection. Input resistance was calculated from the voltage deflection in response to a $-80 \mathrm{pA}$ current pulse. Sag ratio was calculated from a $-200 \mathrm{pA}$ current pulse, by dividing the voltage difference between baseline and the steady state by the difference between baseline and the minimal voltage reach within the first $100 \mathrm{~ms}$ after current injection onset. Rheobase was taken as the current step first seen to elicit an action potential. AP threshold was taken as the membrane potential at the point where $\mathrm{dV} / \mathrm{dt}$ reached $5 \%$ of the maximal $\mathrm{dV} / \mathrm{dt}$. AP height was calculated as the difference between threshold and the peak amplitude of the first AP. Latency was defined as the time between current injection onset and the initial AP in the first sweep where 10 APs were seen. AP half-width was calculated from the first AP, using the time between the half-height of the upward and downward slopes. Inter-spike intervals were calculated as the time difference in onset of subsequent APs, from sweeps where at least $10 \mathrm{APs}$ were elicited. Adaptation was calculated by dividing the intervals between the ninth and tenth APs and the second and third APs. If a cell did not produce ten APs, the sweep with the maximal number of APs was used. Minimal inter-spike interval was taken as the minimum interval between any two consecutive action potentials. Maximum firing frequency was taken as the maximal number of APs produced by current injection. Afterhyperpolarisation (AHP) was calculated as the difference between AP threshold and the minimum voltage seen within 2 ms of AP peak. Medium AHP was defined as the difference between threshold and the minimum voltage seen within $200 \mathrm{~ms}$ of current 
injection offset. Membrane capacitance and membrane time constant were calculated from the voltage response to a -160 pA current injection.

\section{Cell Classification}

Cells were classified into 3 classes based on previous work (Sammons et al. 2019) using a combination of immunohistochemistry and electrophysiological parameters. We used WFS1, parvalbumin (PV) and reelin to approximate the three major cell classes, namely pyramidal neurons, fast-spiking interneurons and non-fast-spiking interneurons respectively. Staining information was available for 272 out of 517 cells. For cells without immunolabelling we took a machine learning approach to classify them to one of the three classes, based on their intrinsic and firing properties. In a few cases not all electrophysiological parameters were available for a cell. In this instance, if staining information was available the mean value of missing parameter from all other cells with the same immunolabel was assigned. If staining information was not available the KNNImputer function (sklearn) was used to assign the missing value. Given that our data belong to a multiclass and imbalanced case (236 WFS1 positive, 28 reelin positive and $8 \mathrm{PV}$ positive neurons), we aimed to select the most accurate classification algorithm for our dataset by testing several models including Complement Naïve Bayes, Logistic Regression, k-Nearest Neighbours Classifier, Random Forest Classifier (RFC), Support Vector Classifier, and Multi-layer Perceptron - Artificial Neural Network (MLP). For each algorithm, we used the subpopulation of neurons with known staining $(n=272)$ to train and test the output performance of the classifier. The GridsearchCV function (Sklearn) was used to identify the best parameters for each model and class weights were calculated and inserted to models where applicable. We used stratification and cross validation to select the two highest performing models (RFC and MLP) and further tested their performance using multiple metrics (Table S1). To produce the final prediction classes for cells without immunolabelling we ran the two top performing algorithms multiple times and took the mode class result. The resulting predictions agreed in $89 \%$ of cells across the two algorithms. Therefore, since both algorithms performed equally well we excluded the minority of cells where the final prediction disagreed from our final dataset $(n=27$ / 245 cells).

\section{Statistics}

Statistics were carried out in python using scipy and statsmodels packages. Data were assessed for a normal distribution using the Shapiro-Wilk test. Where the null-hypothesis was rejected, median and 
interquartile range (IQR) is reported and the Mann-Whitney $U$ test was applied. When the nullhypothesis could not be rejected mean \pm standard deviation $(\mathrm{sd})$ are reported and Student's T-tests were performed. To test whether intersomatic distance had an effect on connectivity rates, the ordinal association test (Cochran-Armitage trend test) was performed. To determine if projection direction had an effect on connection probability a projection distance was calculated for each pair of tested projections by subtracting the minimal distance to pia measure of the postsynaptic cell from the minimal distance to pia of the presynaptic cell. Tested connections were then assigned as either deep-tosuperficial or superficial-to-deep depending on the sign of this sum. Projection distances between \pm 10 $\mu \mathrm{m}$ were excluded from this analysis. A Fisher's exact test was used to compare connection probabilities across the two possible directions. To test whether reciprocal connections were observed more often than expected a simple binomial test was performed, with the hypothesised probability set to the product of the two independent connectivity probabilities.

\section{DATA AND SOFTWARE AVAILABILITY}

\section{Code availability}

Code used for analysis of electrophysiology and cell classification can be found on Github under https://github.com/rosannaps/PaS-analysis.git

\section{RESOURCES TABLE}

\begin{tabular}{|l|l|l|}
\hline REAGENT or RESOURCE & SOURCE & IDENTIFIER \\
\hline Chemicals, Peptides, and Recombinant Proteins & \multicolumn{1}{l|}{} \\
\hline D Glucose & Sigma-Aldrich & CAS 50-99-7 \\
\hline $\mathrm{NaCl}$, & Sigma-Aldrich & CAS 7647-14-5 \\
\hline $\mathrm{KCl}$ & Sigma-Aldrich & CAS 7447-40-7 \\
\hline $\mathrm{NaHCO}_{3}$ & Sigma-Aldrich & CAS 144-55-8 \\
\hline $\mathrm{NaH}_{2} \mathrm{PO}_{4}$ & Sigma-Aldrich & CAS 7558-80-7 \\
\hline $\mathrm{MgCl}_{2}$ & Sigma-Aldrich & CAS 7786-30-3 \\
\hline $\mathrm{CaCl}_{2}$ & Sigma-Aldrich & CAS 10043-52-4 \\
\hline $\mathrm{MgSO}_{4} .7 \mathrm{H}_{2} \mathrm{O}$ & Sigma-Aldrich & CAS 10034-99-8 \\
\hline $\mathrm{Mg}-A T P^{\text {Na-GTP }}$ & Sigma-Aldrich & CAS 74804-12-9 \\
\hline Phosphocreatine Na & Sigma-Aldrich & CAS 360-51-31-7 \\
\hline K-Gluconate & Sigma-Aldrich & CAS 108321-17-1 \\
\hline EGTA & Sigma-Aldrich & CAS 299-27-4 \\
\hline HEPES & Sigma-Aldrich & CAS 67-42-5 \\
\hline Normal goat serum & Sigma-Aldrich & CAS 7365-45-9 \\
\hline Triton-X & Biozol & \\
\hline & Sigma-Aldrich & CAS 9002-93-1 \\
\hline
\end{tabular}




\begin{tabular}{|l|l|l|}
\hline Rabbit anti-WFS1 & Proteintech & RRID: AB_2216046 \\
\hline Mouse anti-reelin & Millipore & RRID: AB_2179313 \\
\hline Mouse anti-PV & SWANT & RRID: AB_2313848 \\
\hline Biocytin & Sigma-Aldrich & CAS 576-19-2 \\
\hline Streptavadin-647 & Thermofisher & RRID: AB_2336066 \\
\hline Anti-mouse AF 555 & Thermofisher & RRID: AB_141822 \\
\hline Anti-rabbit AF 488 & Thermofisher & RRID: AB_2633280 \\
\hline \multicolumn{2}{|l|}{} & \\
\hline Experimental Models: Organisms/Strains & \\
\hline Mouse: C57BL6/NCrl & Charles River Laboratories & IMSR_CRL:27 \\
\hline & & \\
\hline Software and Algorithms & & \\
\hline Spyder & MIT & RRID: SCR_017585 \\
\hline PClamp & Molecular Devices & RRID: SCR_011323 \\
\hline Sklearn & & RRID: SCR_019053 \\
\hline Scipy & & RRID: SCR_008058 \\
\hline Statsmodels & & RRID: SCR_016074 \\
\hline Pandas & & RRID: SCR_018214 \\
\hline Seaborn & & RRID: SCR_018132 \\
\hline Matplotlib & & RRID: SCR_008624 \\
\hline Neo & & RRID: SCR_000634 \\
\hline ImageJ & NIH & RRID: SCR_003070 \\
\hline CellSens & Olympus & RRID: SCR_014551 \\
\hline
\end{tabular}




\section{References}

Amilhon, B., Huh, C.Y.L., Manseau, F., Ducharme, G., Nichol, H., Adamantidis, A., and Williams, S. (2015). Parvalbumin Interneurons of Hippocampus Tune Population Activity at Theta Frequency. Neuron 86, 1277-1289.

Boccara, C.N., Sargolini, F., Thoresen, V.H., Solstad, T., Witter, M.P., Moser, E.I., and Moser, M.-B. (2010). Grid cells in pre- and parasubiculum. Nat. Neurosci. 13, 987-994.

Burak, Y., and Fiete, I.R. (2009). Accurate Path Integration in Continuous Attractor Network Models of Grid Cells. PLOS Comput. Biol. 5, e1000291.

Burgalossi, A., Herfst, L., von Heimendahl, M., Förste, H., Haskic, K., Schmidt, M., and Brecht, M. (2011). Microcircuits of functionally identified neurons in the rat medial entorhinal cortex. Neuron 70 , 773-786.

Burgess, N., Barry, C., and O'Keefe, J. (2007). An oscillatory interference model of grid cell firing. Hippocampus 17, 801-812.

Caballero-Bleda, M., and Witter, M.P. (1993). Regional and laminar organization of projections from the presubiculum and parasubiculum to the entorhinal cortex: an anterograde tracing study in the rat. J. Comp. Neurol. 328, 115-129.

Cossell, L., lacaruso, M.F., Muir, D.R., Houlton, R., Sader, E.N., Ko, H., Hofer, S.B., and Mrsic-Flogel, T.D. (2015). Functional organization of excitatory synaptic strength in primary visual cortex. Nature 518, 399-403.

Couey, J.J., Witoelar, A., Zhang, S.-J., Zheng, K., Ye, J., Dunn, B., Czajkowski, R., Moser, M.-B., Moser, E.I., Roudi, Y., et al. (2013). Recurrent inhibitory circuitry as a mechanism for grid formation. Nat. Neurosci. 16, 318-324.

Ding, S.-L. (2013). Comparative anatomy of the prosubiculum, subiculum, presubiculum, postsubiculum, and parasubiculum in human, monkey, and rodent. J. Comp. Neurol. 521, 4145-4162.

Fuchs, E.C., Neitz, A., Pinna, R., Melzer, S., Caputi, A., and Monyer, H. (2016). Local and Distant Input Controlling Excitation in Layer II of the Medial Entorhinal Cortex. Neuron 89, 194-208.

Funahashi, M., and Stewart, M. (1997). Presubicular and parasubicular cortical neurons of the rat: functional separation of deep and superficial neurons in vitro. J. Physiol. 501 ( Pt 2), 387-403.

Glasgow, S.D., and Chapman, C.A. (2007). Local generation of theta-frequency EEG activity in the parasubiculum. J. Neurophysiol. 97, 3868-3879.

van Groen, T., and Wyss, J.M. (1990). The connections of presubiculum and parasubiculum in the rat. Brain Res. 518, 227-243.

Gu, Y., Lewallen, S., Kinkhabwala, A.A., Domnisoru, C., Yoon, K., Gauthier, J.L., Fiete, I.R., and Tank, D.W. (2018). A Map-like Micro-Organization of Grid Cells in the Medial Entorhinal Cortex. Cell 175, 736-750.e30.

Guzman, S.J., Schlögl, A., and Schmidt-Hieber, C. (2014). Stimfit: quantifying electrophysiological data with Python. Front. Neuroinformatics 8.

Guzman, S.J., Schlögl, A., Frotscher, M., and Jonas, P. (2016). Synaptic mechanisms of pattern completion in the hippocampal CA3 network. Science 353, 1117-1123.

Hafting, T., Fyhn, M., Molden, S., Moser, M.-B., and Moser, E.I. (2005). Microstructure of a spatial map in the entorhinal cortex. Nature 436, 801-806.

Hasselmo, M.E., Giocomo, L.M., and Zilli, E.A. (2007). Grid cell firing may arise from interference of theta frequency membrane potential oscillations in single neurons. Hippocampus 17, 1252-1271. 
bioRxiv preprint doi: https://doi.org/10.1101/2020.12 18.423400; this version posted December $19,2020$. The copyright holder for this preprint (which was not certified by peer review) is the author/funder, who has granted bioRxiv a license to display the preprint in perpetuity. It is made available under aCC-BY-NC-ND 4.0 International license.

Heys, J.G., Rangarajan, K.V., and Dombeck, D.A. (2014). The functional micro-organization of grid cells revealed by cellular-resolution imaging. Neuron 84, 1079-1090.

Hofer, S.B., Ko, H., Pichler, B., Vogelstein, J., Ros, H., Zeng, H., Lein, E., Lesica, N.A., and MrsicFlogel, T.D. (2011). Differential connectivity and response dynamics of excitatory and inhibitory neurons in visual cortex. Nat. Neurosci. 14, 1045-1052.

Ishihara, Y., and Fukuda, T. (2016). Immunohistochemical investigation of the internal structure of the mouse subiculum. Neuroscience 337, 242-266.

Ko, H., Hofer, S.B., Pichler, B., Buchanan, K.A., Sjöström, P.J., and Mrsic-Flogel, T.D. (2011). Functional specificity of local synaptic connections in neocortical networks. Nature 473, 87-91.

Köhler, C. (1986). Intrinsic connections of the retrohippocampal region in the rat brain. II. The medial entorhinal area. J. Comp. Neurol. 246, 149-169.

Lefort, S., Tomm, C., Floyd Sarria, J.-C., and Petersen, C.C.H. (2009). The Excitatory Neuronal Network of the C2 Barrel Column in Mouse Primary Somatosensory Cortex. Neuron 61, 301-316.

Luuk, H., Koks, S., Plaas, M., Hannibal, J., Rehfeld, J.F., and Vasar, E. (2008). Distribution of Wfs1 protein in the central nervous system of the mouse and its relation to clinical symptoms of the Wolfram syndrome. J. Comp. Neurol. 509, 642-660.

McNaughton, B.L., Battaglia, F.P., Jensen, O., Moser, E.I., and Moser, M.-B. (2006). Path integration and the neural basis of the "cognitive map." Nat. Rev. Neurosci. 7, 663-678.

Miyoshi, G., Hjerling-Leffler, J., Karayannis, T., Sousa, V.H., Butt, S.J.B., Battiste, J., Johnson, J.E., Machold, R.P., and Fishell, G. (2010). Genetic Fate Mapping Reveals That the Caudal Ganglionic Eminence Produces a Large and Diverse Population of Superficial Cortical Interneurons. J. Neurosci. 30, 1582-1594.

Moser, M.-B., Rowland, D.C., and Moser, E.I. (2015). Place Cells, Grid Cells, and Memory. Cold Spring Harb. Perspect. Biol. 7, a021808.

Mulders, W.H., West, M.J., and Slomianka, L. (1997). Neuron numbers in the presubiculum, parasubiculum, and entorhinal area of the rat. J. Comp. Neurol. 385, 83-94.

Peng, Y., Barreda Tomás, F.J., Klisch, C., Vida, I., and Geiger, J.R.P. (2017). Layer-Specific Organization of Local Excitatory and Inhibitory Synaptic Connectivity in the Rat Presubiculum. Cereb. Cortex N. Y. N 1991 27, 2435-2452.

Perin, R., Berger, T.K., and Markram, H. (2011). A synaptic organizing principle for cortical neuronal groups. Proc. Natl. Acad. Sci. 108, 5419-5424.

Preston-Ferrer, P., Coletta, S., Frey, M., and Burgalossi, A. (2016). Anatomical organization of presubicular head-direction circuits. ELife 5, e14592.

Rudy, B., Fishell, G., Lee, S., and Hjerling-Leffler, J. (2011). Three groups of interneurons account for nearly $100 \%$ of neocortical GABAergic neurons. Dev. Neurobiol. 71, 45-61.

Sammons, R.P., Parthier, D., Stumpf, A., and Schmitz, D. (2019). Electrophysiological and Molecular Characterization of the Parasubiculum. J. Neurosci. Off. J. Soc. Neurosci. 39, 8860-8876.

Seeman, S.C., Campagnola, L., Davoudian, P.A., Hoggarth, A., Hage, T.A., Bosma-Moody, A., Baker, C.A., Lee, J.H., Mihalas, S., Teeter, C., et al. (2018). Sparse recurrent excitatory connectivity in the microcircuit of the adult mouse and human cortex. ELife 7, e37349.

Simonnet, J., Nassar, M., Stella, F., Cohen, I., Mathon, B., Boccara, C.N., Miles, R., and Fricker, D. (2017). Activity dependent feedback inhibition may maintain head direction signals in mouse presubiculum. Nat. Commun. 8, 16032. 
bioRxiv preprint doi: https://doi org/10.1101/2020.1218.423400; this version posted December $19,2020$. The copyright holder for this preprint (which was not certified by peer review) is the author/funder, who has granted bioRxiv a license to display the preprint in perpetuity. It is made available under aCC-BY-NC-ND 4.0 International license.

Song, S., Sjöström, P.J., Reigl, M., Nelson, S., and Chklovskii, D.B. (2005). Highly Nonrandom Features of Synaptic Connectivity in Local Cortical Circuits. PLOS Biol. 3, e68.

Stark, E., Eichler, R., Roux, L., Fujisawa, S., Rotstein, H.G., and Buzsáki, G. (2013). Inhibition-induced theta resonance in cortical circuits. Neuron 80.

Sun, C., Kitamura, T., Yamamoto, J., Martin, J., Pignatelli, M., Kitch, L.J., Schnitzer, M.J., and Tonegawa, S. (2015). Distinct speed dependence of entorhinal island and ocean cells, including respective grid cells. Proc. Natl. Acad. Sci. U. S. A. 112, 9466-9471.

Tang, Q., Burgalossi, A., Ebbesen, C.L., Sanguinetti-Scheck, J.I., Schmidt, H., Tukker, J.J., Naumann, R., Ray, S., Preston-Ferrer, P., Schmitz, D., et al. (2016). Functional Architecture of the Rat Parasubiculum. J. Neurosci. Off. J. Soc. Neurosci. 36, 2289-2301.

Taube, J.S. (1995). Place cells recorded in the parasubiculum of freely moving rats. Hippocampus 5 , 569-583.

Tukker, J.J., Tang, Q., Burgalossi, A., and Brecht, M. (2015). Head-Directional Tuning and Theta Modulation of Anatomically Identified Neurons in the Presubiculum. J. Neurosci. 35, 15391-15395.

Unal, G., Joshi, A., Viney, T.J., Kis, V., and Somogyi, P. (2015). Synaptic Targets of Medial Septal Projections in the Hippocampus and Extrahippocampal Cortices of the Mouse. J. Neurosci. Off. J. Soc. Neurosci. 35, 15812-15826.

Winterer, J., Maier, N., Wozny, C., Beed, P., Breustedt, J., Evangelista, R., Peng, Y., D’Albis, T., Kempter, R., and Schmitz, D. (2017). Excitatory Microcircuits within Superficial Layers of the Medial Entorhinal Cortex. Cell Rep. 19, 1110-1116.

Yoshimura, Y., and Callaway, E.M. (2005). Fine-scale specificity of cortical networks depends on inhibitory cell type and connectivity. Nat. Neurosci. 8, 1552-1559.

Yoshimura, Y., Dantzker, J.L.M., and Callaway, E.M. (2005). Excitatory cortical neurons form finescale functional networks. Nature 433, 868-873.

Yu, Y.-C., Bultje, R.S., Wang, X., and Shi, S.-H. (2009). Specific synapses develop preferentially among sister excitatory neurons in the neocortex. Nature 458, 501-504. 

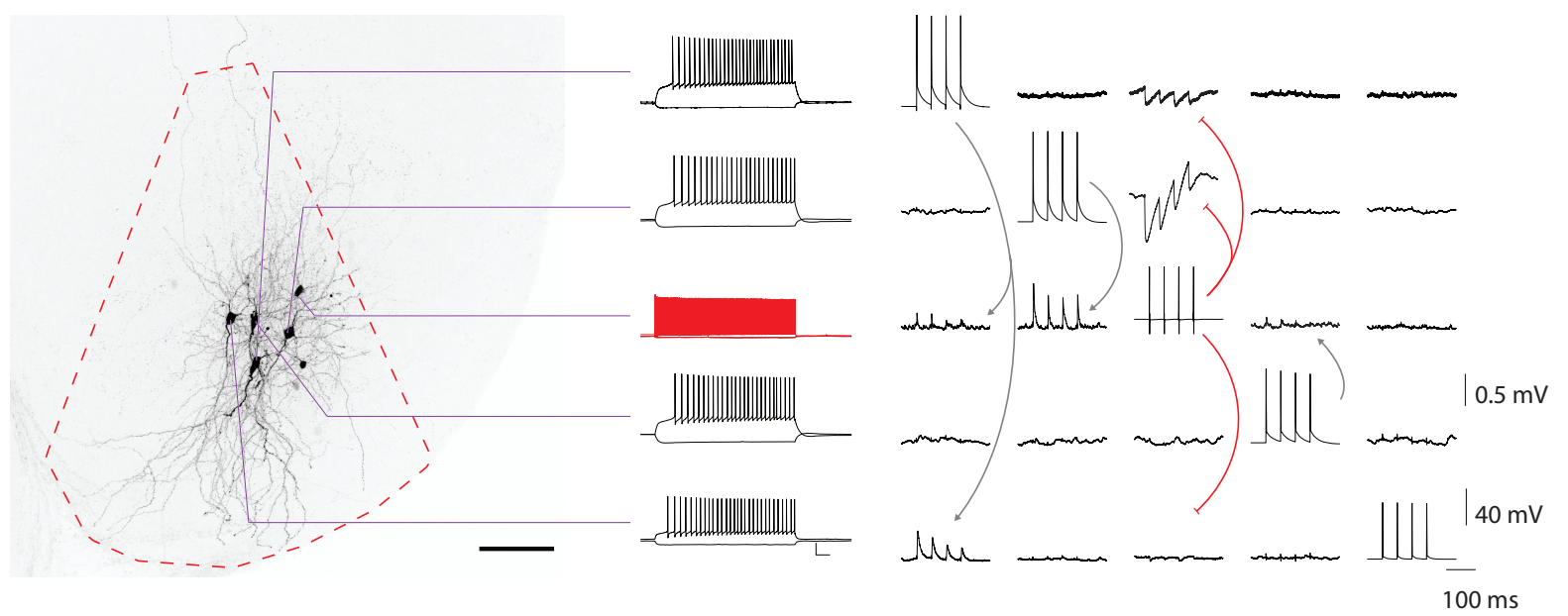

B

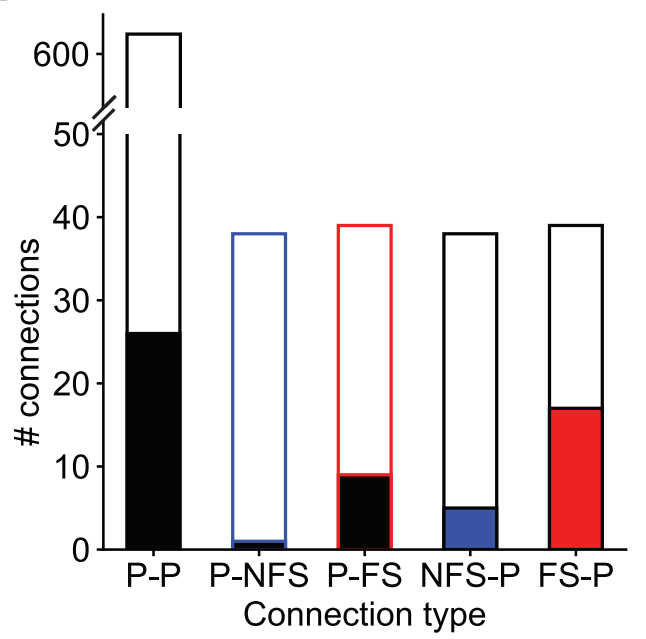

C

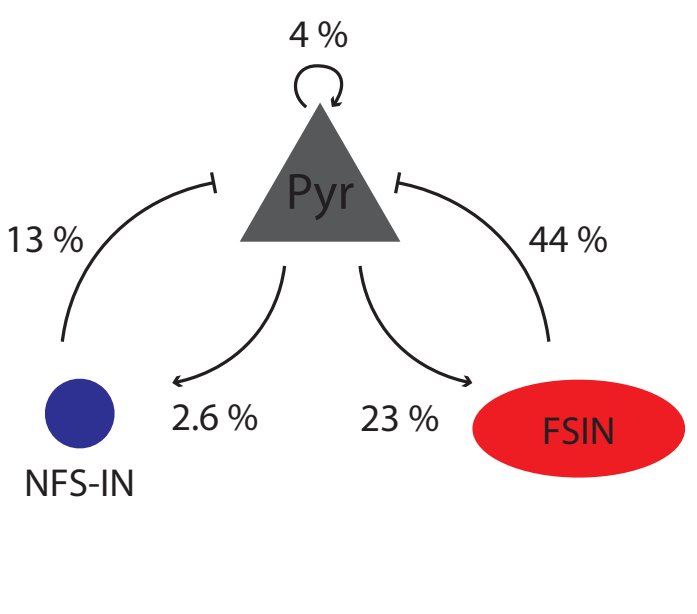

Figure 1. Connectivity rates across the three major cell classes in the parasubiculum. A) Biocytin labelling of a cluster of 5 recorded neurons. B) Left, firing profile of the cells shown in A. Right, connectivity screen. Each cell is consecutively stimulated to fire 4 APs while the postsynaptic cell membrane potential is monitored. C) Numbers of tested and found connections between the different cell classes. Filled bars indicate found connections, unfilled shows number of tested connections. D) Summary of connectivity rates between pyramidal neurons and the two subgroups of interneurons in the parasubiculum. 
A1

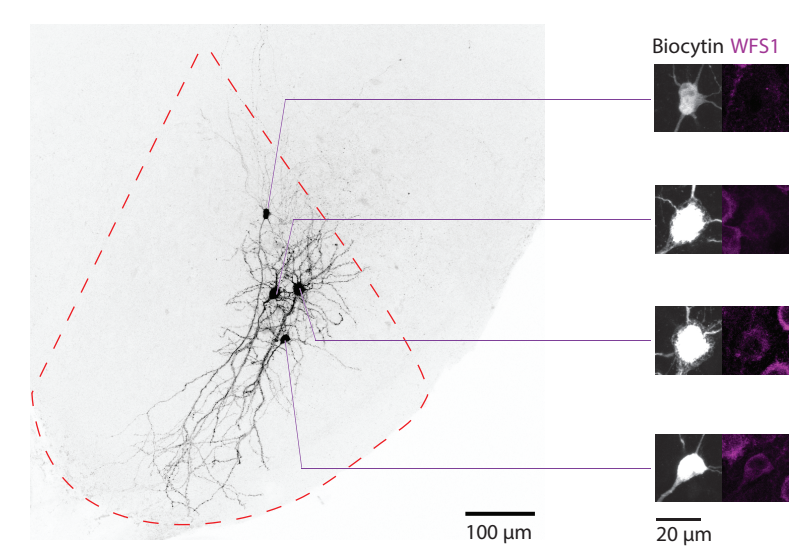

B

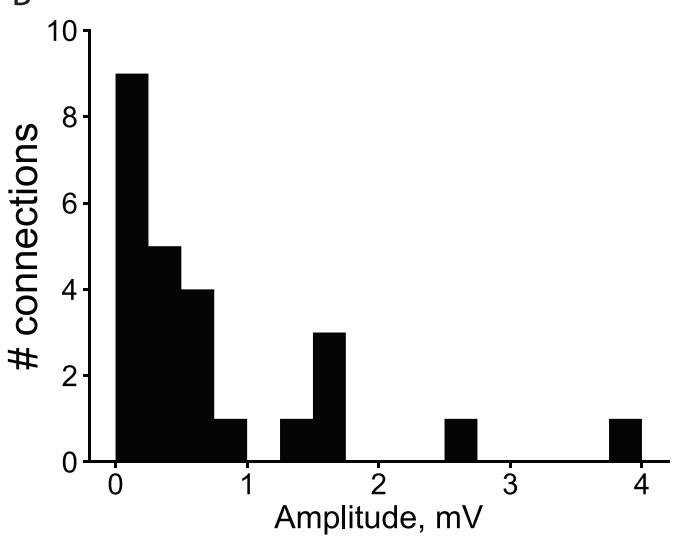

$\mathrm{F}$

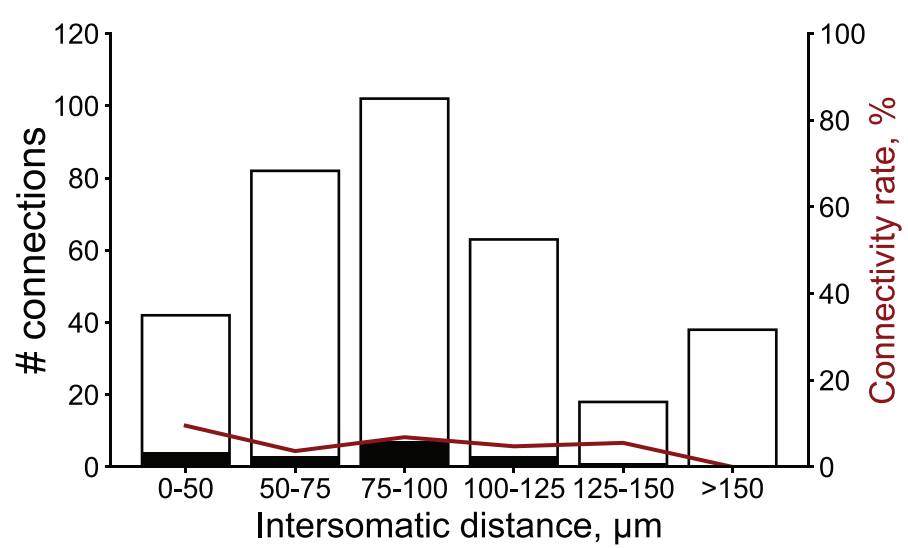

A2

C

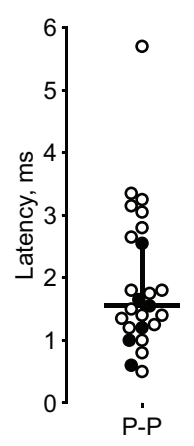

D

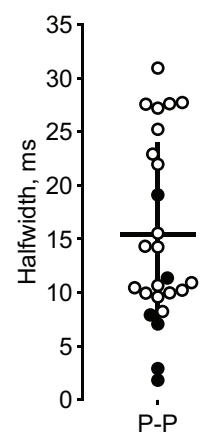

E $\quad$ unidirectional

- bidirectional
G

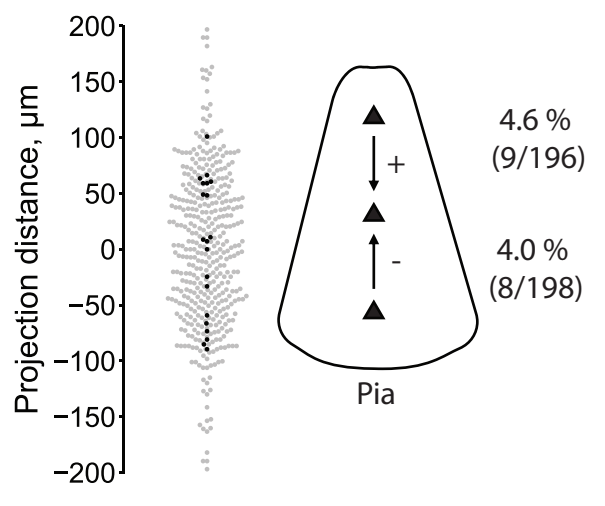

Figure 2. Pyramid to pyramid connections. A1) Biocytin labelling of four simultaneously recorded pyramidal neurons in the parasubiculum. Right, close of up somas and WFS1 labelling. In the top cell WFS1 labelling was not detected but the cell was classified as a pyramidal neuron based on electrophysiological properties. A2) Left, firing profiles and right, connectivity screen between 4 cells shown in A1. B) Histogram of EPSP amplitudes for pyramid to pyramid connections. $p=0.548$, ShapiroWilk test on log-transformed values. C) Latency times of EPSPs for pyramid to pyramid connections. D) Halfwidth of EPSPs in pyramid to pyramid connections. E) Rise time of EPSPs in pyramidal connections. F) Distance dependence of pyramidal connectivity. Empty bars indicate total number of tested 
connections for each bin; filled bars indicate connections found. Red line represents connectivity rate (right axis). No distance-dependence in connection probability was seen using the ordinal association test $(p=0.242)$. G) Laminar directional dependence of connectivity. Left, grey points indicate tested connections with no connectivity, black points indicate found connections. Inset, schematic summarises calculation method such that a positive value indicates deep-to-superficial connection and a negative value indicates superficial-to-deep connection. No directional-dependence was seen in connection probability using the Fisher's exact test to compare connection probability from deep-to-superficial cells versus superficial-to-deep cells $(p=0.810)$. 

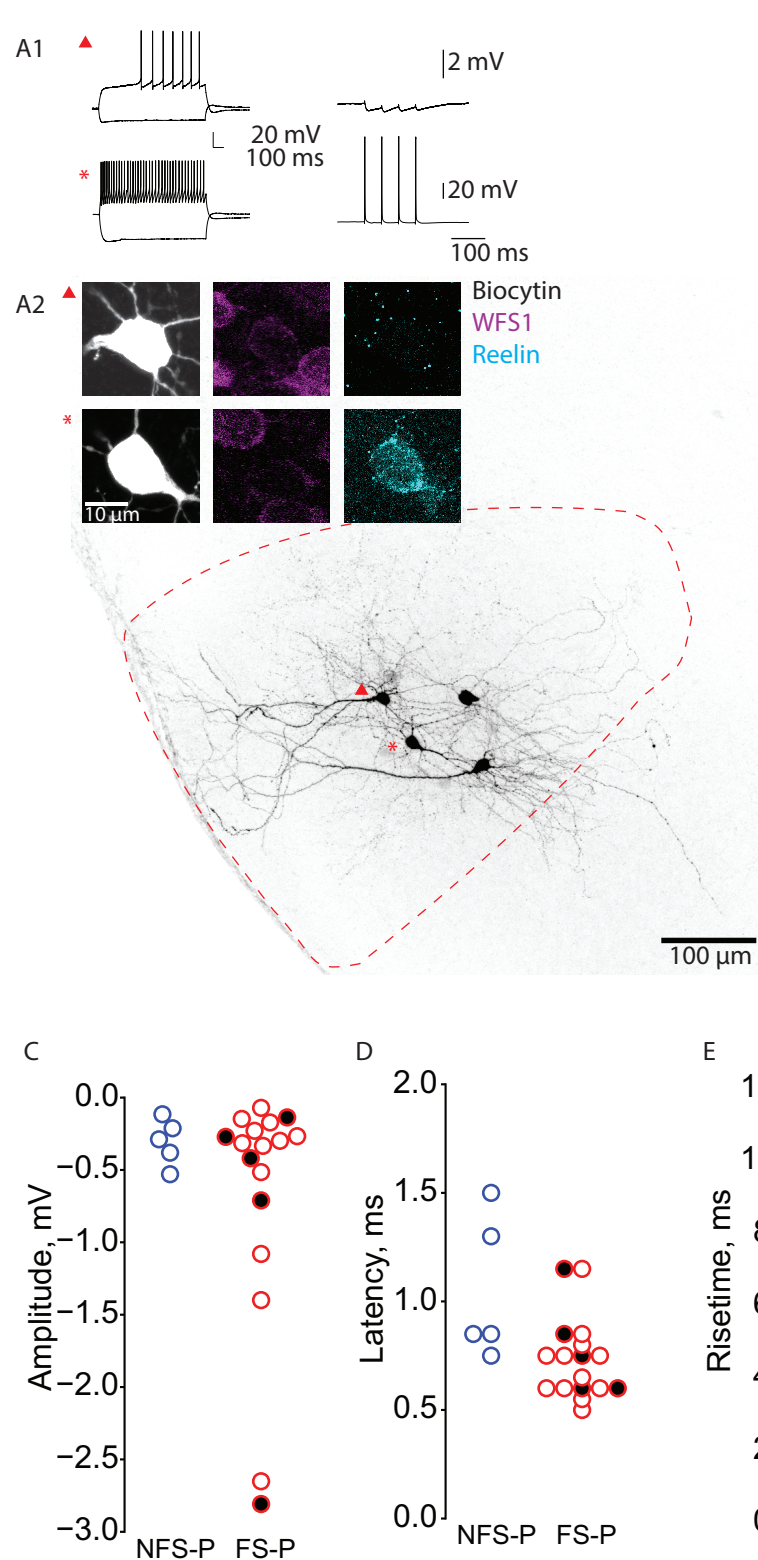

G

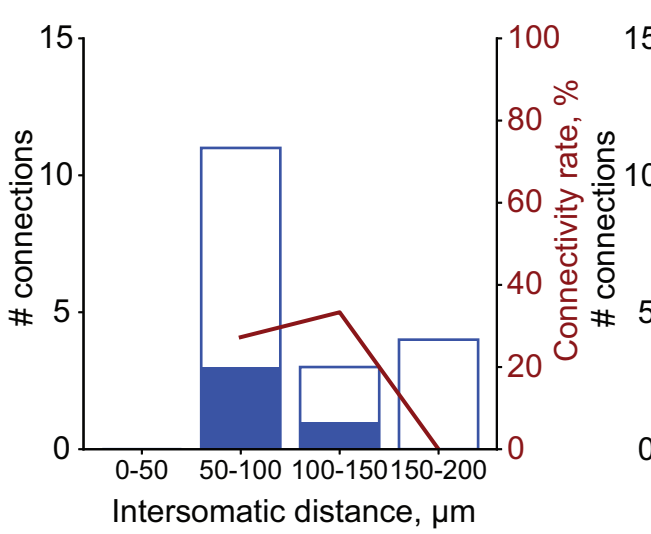

D

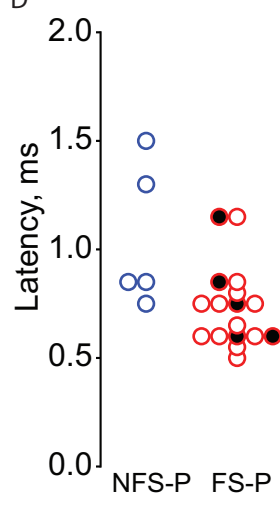

$H$
B1

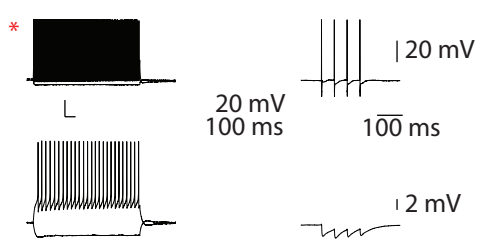

B2
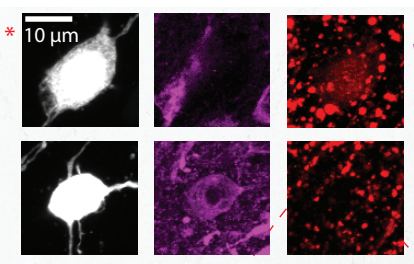

$\mathrm{E}$

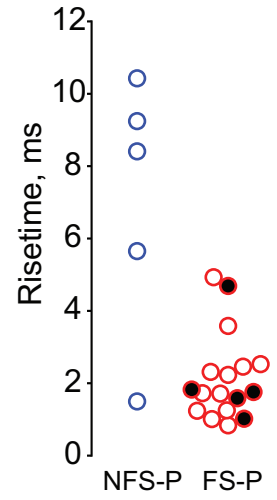

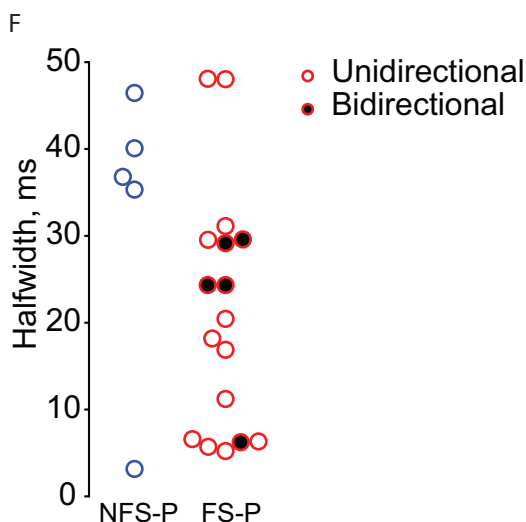

I

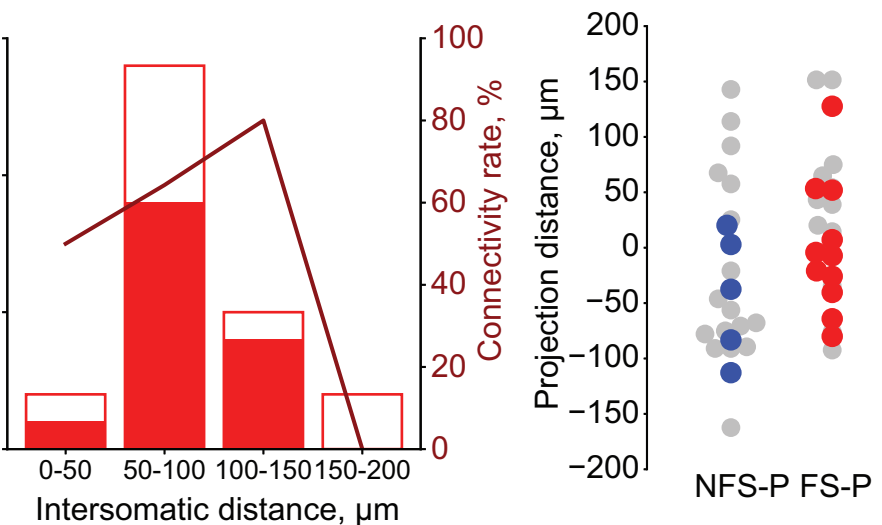

Figure 3. Inhibitory inputs onto pyramidal neurons. A1) Left, firing profiles of a pyramidal neuron and non-fast-spiking interneuron. Right, presynaptic action potentials and corresponding postsynaptic 
response. A2) Immunolabelling and biocytin filling of the corresponding neurons. B1) Left, firing profiles of a fast-spiking interneuron and a pyramidal neuron. Right, presynaptic action potentials and corresponding postsynaptic response. B2) Immunolabelling and biocytin filling of the corresponding cells. C) Amplitude of ISPSs from the two classes of interneurons onto pyramidal-like neurons. D) Latency of IPSPs from the two interneuron classes onto pyramidal-like neurons. E) Risetime of IPSPS from the two interneurons classes onto pyramidal-type neurons. F) Halfwidth of IPSPs onto pyramidaltype neurons. G) Connectivity rate between non-fast-spiking interneurons and pyramidal neurons binned by intersomatic distance. Connectivity rate does not differ significantly across distance, $p=0.501$, ordinal association test. H) Connectivity rate between fast-spiking interneurons and pyramidal neurons binned by intersomatic distance. Connectivity rate does not vary significantly across distance, $p=0.611$, ordinal association test. I) Projection distances between presynaptic non-fast-spiking (left, blue) or fastspiking (right, red) interneurons and postsynaptic pyramidal neurons. Grey dots indicate tested connections, coloured dots indicate found connections. Non-fast-spiking interneurons to pyramids: deep-to-superficial: 1 / 7 connected, superficial-to-deep: 3 / 14 connected; $p=0.999$, Fisher's exact test. Fast-spiking interneurons to pyramids: deep-to-superficial: 3 / 12 connected, superficial-to-deep: 5 / 8 connected; $p=0.167$, Fisher's exact test. 

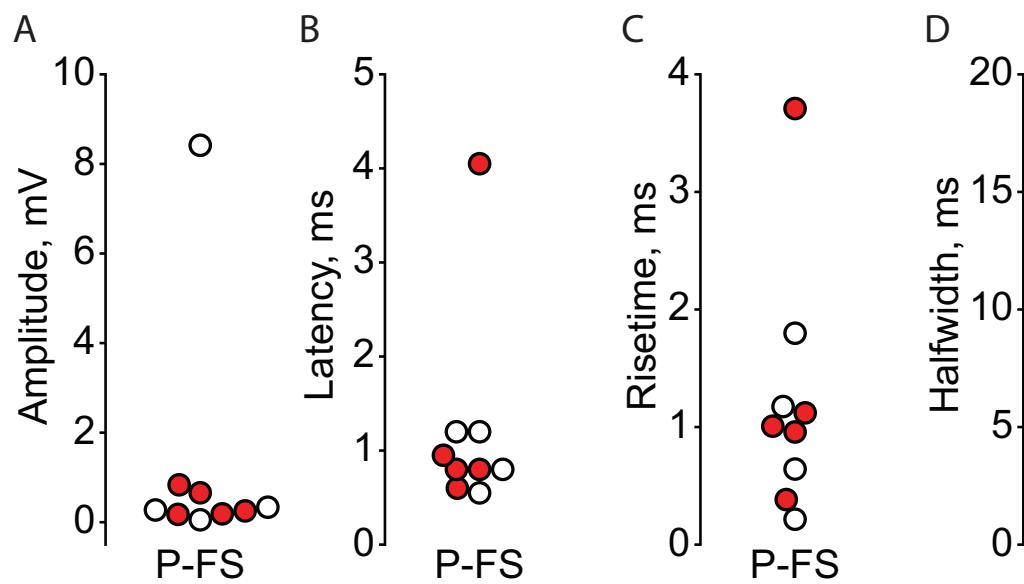

- Bidirectional

- Unidirectional

E

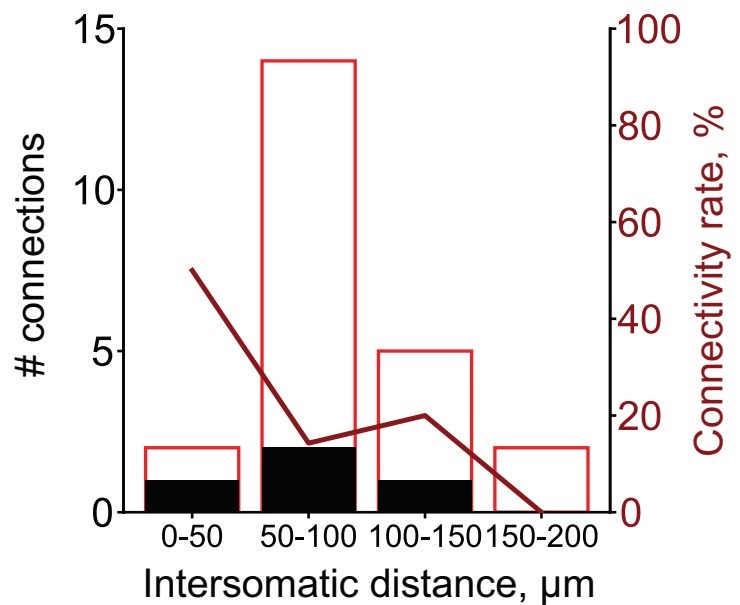

$\mathrm{F}$

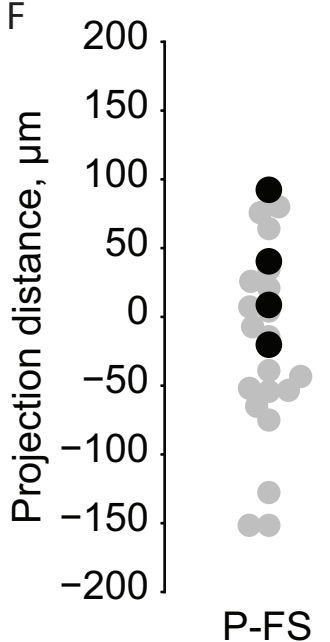

Figure 4. Connections from pyramidal neurons onto fast-spiking interneurons

A) Amplitudes of connections from pyramidal neurons onto fast-spiking interneurons. B) Latency of connections from pyramidal neurons onto fast-spiking interneurons. C) Risetime of EPSPs from pyramids onto fast-spiking neurons. D) Halfwidth of EPSPs from pyramids onto fast-spiking interneurons. E) Rate of connectivity across different intersomatic distances between pyramidal neurons and fast-spiking interneurons. No statistical difference was seen in connectivity rate across intersomatic distances $(p=0.430$, ordinal association test). F) Projection distances between pyramids onto fastspiking interneurons. Deep-to-superficial: 2 / 8 connected, superficial-to-deep: $1 / 12$ connected, $p=$ 0.537 , Fisher's exact test. 
Supplementary Material

Supplementary Table 1. Validation and performance of cell classification algorithms

Supplementary Table 2. Electrophysiological properties of the three classes of classified cells in the parasubiculum

Supplementary Table 3. Properties of uni- and bidirectional connections

Table S1

\begin{tabular}{|l|c|c|c|c|c|c|}
\hline & Accuracy & $\begin{array}{c}\text { Balanced } \\
\text { Accuracy }\end{array}$ & Precision & Recall & F1 Score & ROC AUC score \\
\hline RF & $0.94 /(0.007)$ & $0.87 /(0.04)$ & $0.916 /(0.06)$ & $0.878 /(0.04)$ & $0.88 /(0.029)$ & $0.97 /(0.029)$ \\
\hline MLP & $0.948 /(0.02)$ & $0.88 /(0.075)$ & $0.93 /(0.025)$ & $0.88 /(0.07)$ & $0.89 /(0.05)$ & $0.96 /(0.036)$ \\
\hline
\end{tabular}

Mean and std range for performance metrics of RF and MLP classification models. 


\section{Table S2}

\begin{tabular}{|c|c|c|c|}
\hline & Pyramid & $\begin{array}{l}\text { Non-fast-spiking } \\
\text { interneuron }\end{array}$ & $\begin{array}{l}\text { Fast-spiking } \\
\text { interneuron }\end{array}$ \\
\hline $\mathrm{Vm}(\mathrm{mV})$ & $-66.3(-71.4--60.2)$ & $-65(-70.5--60.6)$ & $-65.8(-72--62.3)$ \\
\hline Input resistance (M $\Omega$ ) & $106.3(80.1-133.9)$ & $211.4(148.2-271.9)$ & $55.7(48.3-73.1)$ \\
\hline Sag Ratio & $0.89(0.85-0.92)$ & $0.9(0.85-0.93)$ & $0.92(0.89-0.95)$ \\
\hline Membrane time constant (ms) & $9.6(7.7-11.8)$ & $6.8(5.1-10.3)$ & $4(3.4-4.4)$ \\
\hline Membrane capacitance $(p F)$ & $106.7(85.2-129.4)$ & $47.7(30.6-56.6)$ & $74.8(59.8-87.9)$ \\
\hline Rheobase (pA) & $160(120-200)$ & $80(40-120)$ & $400(280-500)$ \\
\hline AP threshold (mV) & $-33.3(-35.7--31.4)$ & $-33.8(-36.6--31.1)$ & $-32.6(-36.5--30.3)$ \\
\hline AP half-width (ms) & $0.69(0.61-0.79)$ & $0.68(0.50-0.83)$ & $0.24(0.21-0.27)$ \\
\hline AP height $(\mathrm{mV})$ & $65.9(58.9-71.6)$ & $48.5(44.1-59.3)$ & $48.7(45-55.4)$ \\
\hline Onset latency (ms) & $288.7(176.7-498)$ & $83.8(41-145.9)$ & $34.1(8.4-319.9)$ \\
\hline $\operatorname{Max} \mathrm{dV} / \mathrm{dt}\left(\mathrm{V} . \mathrm{s}^{-1}\right)$ & $254(195-316)$ & $179(135-256)$ & $354(286-417)$ \\
\hline $\operatorname{Min} \mathrm{dV} / \mathrm{dt}\left(\mathrm{V} . \mathrm{s}^{-1}\right)$ & $-106(-125--86)$ & $-96(-134--66)$ & $-282(-346--220)$ \\
\hline $\mathrm{dV} / \mathrm{dt}$ ratio & $2.4(2.0-2.8)$ & $1.9(1.6-2.2)$ & $1.2(1.1-1.3)$ \\
\hline AP1-AP2 int. (ms) & $66.3(52.7-76.8)$ & $29(18.5-40.4)$ & $9.5(7.6-17.3)$ \\
\hline AP9-AP10 int. (ms) & $58(47.4-72.6)$ & $37.1(27.2-56)$ & $10.4(8.1-17.2)$ \\
\hline Adaptation index & $0.94(0.82-1.12)$ & $1.13(0.82-1.44)$ & $1.02(0.75-1.21)$ \\
\hline Min. ISI (ms) & $10.6(7.8-16.4)$ & $4.2(3.6-5)$ & $3.9(3-5.4)$ \\
\hline Max. firing freq $(\mathrm{Hz})$ & $51(37-65)$ & $91(61-119)$ & $229(160-302)$ \\
\hline $\mathrm{AHP}(\mathrm{mV})$ & $15.8(13.3-18.3)$ & $18(14.9-21.4)$ & $25.7(23.4-27.6)$ \\
\hline $\mathrm{mAHP}(\mathrm{mV})$ & $2.3(0.9-3.5)$ & $2(0.7-4.4)$ & $1.7(1.1-2.6)$ \\
\hline
\end{tabular}


Table S3

\begin{tabular}{|c|c|c|c|c|c|c|c|c|c|}
\hline \multicolumn{2}{|c|}{ Connection type } & Amplitude, mV & $p$-value & Latency, ms & $p$-value & Halfwidth, ms & $p$-value & Risetime, ms & $\mathrm{p}$-value \\
\hline \multirow{2}{*}{ Pyr-Pyr } & Unidirectional, $n=19$ & $0.47(0.18-1.46)$ & \multirow{2}{*}{0.107} & $1.8(1.3-2.9)$ & \multirow{2}{*}{0.107} & $14.3,(10.3-26.2)$ & \multirow{2}{*}{0.009} & $2.2(1.6-3.0)$ & \multirow{2}{*}{0.026} \\
\hline & Bidirectional, $n=6$ & $0.23(0.16-0.49)$ & & $1.4(1.1-1.6)$ & & $7.5,(3.9-10.5)$ & & $1.0(0.6-1.6)$ & \\
\hline \multirow{2}{*}{ Pyr-FS } & Unidirectional, $n=5$ & $0.30(0.22-2.36)$ & \multirow{2}{*}{0.451} & $1.0(0.7-1.2)$ & \multirow{2}{*}{0.450} & $9.6,(5.0-14.2)$ & \multirow{2}{*}{0.270} & $0.9(0.5-1.3)$ & \multirow{2}{*}{0.451} \\
\hline & Bidirectional, $n=4$ & $0.25(0.19-0.66)$ & & $0.8(0.8-1.0)$ & & $6.0,(3.4-6.4)$ & & $1.0(1.0-1.1)$ & \\
\hline \multirow{2}{*}{ FS-Pyr } & Unidirectional, $n=12$ & $-0.31(-0.66--0.21)$ & \multirow{2}{*}{0.318} & $0.7(0.6-0.8)$ & \multirow{2}{*}{0.259} & $17.5(6.5-29.9)$ & \multirow{2}{*}{0.318} & $2.0(1.2-2.5)$ & \multirow{2}{*}{0.479} \\
\hline & Bidirectional, $n=5$ & $-0.42(-0.71--0.27)$ & & $0.7(0.6-0.9)$ & & $24.3(24.3-29.2)$ & & $1.8(1.6-1.8)$ & \\
\hline
\end{tabular}

Median and interquartile range for connection parameters in uni- and bidirectional connections of different synaptic pairings. p-values are calculated from MannWhitney $U$ test. 